\title{
The rat anococcygeus muscle and its response to nerve stimulation and to some drugs
}

\author{
J. S. GILLESPIE \\ Department of Pharmacology, Glasgow University, Scotland
}

\section{Summary}

1. A new smooth muscle preparation, the rat anococcygeus muscle, is described. The muscle is paired, thin, consists of smooth muscle only and the muscle cells are organized in parallel bundles. It has a dense adrenergic innervation distributed throughout the muscle but apparently no cholinergic innervation. The muscles are easily isolated.

2. The muscle contracts to noradrenaline, acetylcholine, furmethide, 5 . hydroxytryptamine, but not to histamine. Isoprenaline produces contraction at high concentrations. The effects of noradrenaline and acetylcholine are blocked by phentolamine and atropine respectively. The response to isoprenaline is little affected by propranolol.

3. The muscle contracts in response to field stimulation or stimulation of extrinsic nerves. This response is completely blocked by phentolamine but unaffected by hexamethonium or atropine.

4. Guanethidine $10^{-6}-5 \times 10^{-6} \mathrm{M}$ blocks the motor response to nerve stimulation and potentiates that to noradrenaline. Higher concentrations of guanethidine raise tone. In the presence of raised tone, field stimulation produces an inhibitory response insensitive to hexamethonium but abolished by tetrodotoxin $2 \times 10^{-7} \mathrm{~g} / \mathrm{ml}$. This inhibitory response to stimulation can also be shown after other drugs which raise tone.

5. The inhibitory response to nerve stimulation is not mimicked by acetylcholine, isoprenaline or ATP, nor blocked by atropine, phentolamine, phenoxybenzamine, propranolol, hexamethonium or lysergic acid diethylamide.

\section{Introduction}

Smooth muscles differ so widely in their properties that it would be unreasonable to propose a preparation representative of all ; nonetheless there would be general agreement that for experimental purposes certain properties are desirable. First, the preparation should consist of smooth muscle cells only, these cells arranged in parallel bundles to form a thin sheet. Such an arrangement minimizes the problem of diffusion for drug access and in ion exchange studies. The muscle should be bilateral so that control and test preparations can be taken from the same animal. For studies of autonomic control it should be densely innervated, ideally by both motor and inhibitor nerves. No existing preparation fulfils all of these requirements. In particular, since most smooth muscle is found in the walls of hollow viscera, the geometric arrangement is often circular or helical, introducing difficulties in the interpretation of mechanical responses. The rat anococcygeus muscle. 
however, appears to possess all of these desirable features and has not previously been used for experimental work. This article describes some of the basic pharmacological properties of this new preparation. In addition to a dense adrenergic motor innervation, the preparation has been found to possess an inhibitory innervation whose transmitter is as yet unknown. A preliminary account of these results has been published (Gillespie, 1971).

\section{Methods}

The two anococcygeus muscles arise from the upper coccygeal vertebrae close to one another in the midline of the pelvic cavity. The muscles pass caudally, lying first behind and then to one side of the colon, finally joining together to form a ventral bar in front of the colon a few $\mathrm{mm}$ from the anus. The extrinsic nerves pass in a branch of the perineal nerve on either side to enter the deep surface of each muscle just short of the formation of the ventral bar.

Rats were killed by a blow on the head, and bled. The abdomen was opened in the mid-line, the pelvis split and the bladder and urethra removed. Care was required in clearing the lower part of the urethra to avoid damage to the ventral bar of muscle, the only region lying ventral to the colon. The colon was then cut through at the pelvic brim, the pelvic portion pulled forward and the delicate connective tissue behind cleared until the anococcygeus muscles came into view. The muscles were isolated, in some instances with the extrinsic nerve intact. The extrinsic nerves on either side run in the posterior scrotal branch of the perineal nerve and leave it to enter the deep surface of the anococcygeal muscles as they lie on the lateral surface of the colon. The ventral bar was cut through and each muscle mounted in a $100 \mathrm{ml}$ bath containing Krebs solution at $36^{\circ} \mathrm{C}$. The solution was gassed with $95 \% \mathrm{O}_{2}+5 \% \mathrm{CO}_{2}$. Tension was measured with Grass FT 03 isometric transducers and displayed on a Grass Polygraph. Field stimulation of the intramural nerve fibres was applied after drawing the muscles through a pair of electrodes similar to those described by Burn \& Rand (1960); when the muscles were stimulated through their extrinsic nerves the nerves were drawn through similar electrodes. Stimulation of either intramural or extrinsic nerves was with $1 \mathrm{~ms}$ pulses at $20 \mathrm{~Hz}$, and at supramaximal voltage ; other frequencies when used are indicated in the text.

The adrenergic innervation of the muscle was examined histologically on freeze dried tissue with a slightly modified version of the technique of Hillarp \& Falck (Gillespie \& Kirpekar, 1966). The tissue was also examined for evidence of a cholinergic innervation by staining for cholinesterase with the thiocholine method of Koelle (1955). Muscles were either lightly fixed in 10\% Baker's buffered formalin for 16 hours or the whole muscle stretched on a plastic frame and air dried. Control sections from rat intercostal muscles were taken through along with the anococcygeus muscles as a control. In other controls butyrylcholinesterase was inhibited with either Mipafox $10^{-6} \mathrm{M}$ or iso-OMPA $10^{-6} \mathrm{M}$, and acetylcholinesterase with BW 284 c $51 \quad 10^{-6} \mathrm{M}$.

Drugs used were (-)-noradrenaline bitartrate, (-)-isoprenaline hydrochloride, acetylcholine chloride, 5-hydroxytryptamine creatine sulphate $(5-\mathrm{HT})$, histamine acid phosphate, phentolamine mesylate, ( \pm )-propranolol hydrochloride, atropine sulphate, guanethidine sulphate. phenoxybenzamine hydrochloride, tetrodotoxin. Doses refer to the base with the exception of tetrodotoxin. 
Results

\section{Muscle innervation}

It has already been reported (Gillespie \& Maxwell, 1971) that the muscle has a dense adrenergic innervation distributed through the muscle fibres and resembling that of the nictitating membrane. The distribution of terminal varicose fibres was uniform except in the lower (caudal) part of each muscle. There, in addition to the fibres scattered throughout the muscle mass, there was a concentration of adrenergic fibres as a single layer of bright beaded points along the surface layer of muscle cells. The entry of the less bright preterminal nerve bundles could also be seen in this area. No evidence of either butyryl or acetylcholinesterase was found, either in muscle sections or in unstained whole mounts.

\section{Motor responses}

\section{The effect of sympathomimetics, 5-hydroxytryptamine and histamine}

The anococcygeus muscle in vitro had neither spontaneous activity nor tone. It contracted strongly, however, in response to noradrenaline (Fig. 1). The threshold was low, usually about $10^{-7} \mathrm{M}$; increasing the concentration resulted in a graded increase in contraction and maximum responses were obtained with about $10^{-4} \mathrm{M}$. The effect of noradrenaline was abolished by phentolamine $10^{-6} \mathrm{M}$ and doseresponse curves showed a parallel shift characteristic of competitive antagonism.

Isoprenaline, in contrast, had no visible effect on the muscle until high concentrations of about $10^{-5} \mathrm{M}$ were reached and these caused contraction (Fig. 2). The possibility that lower concentrations were exercising an inhibitory effect masked by

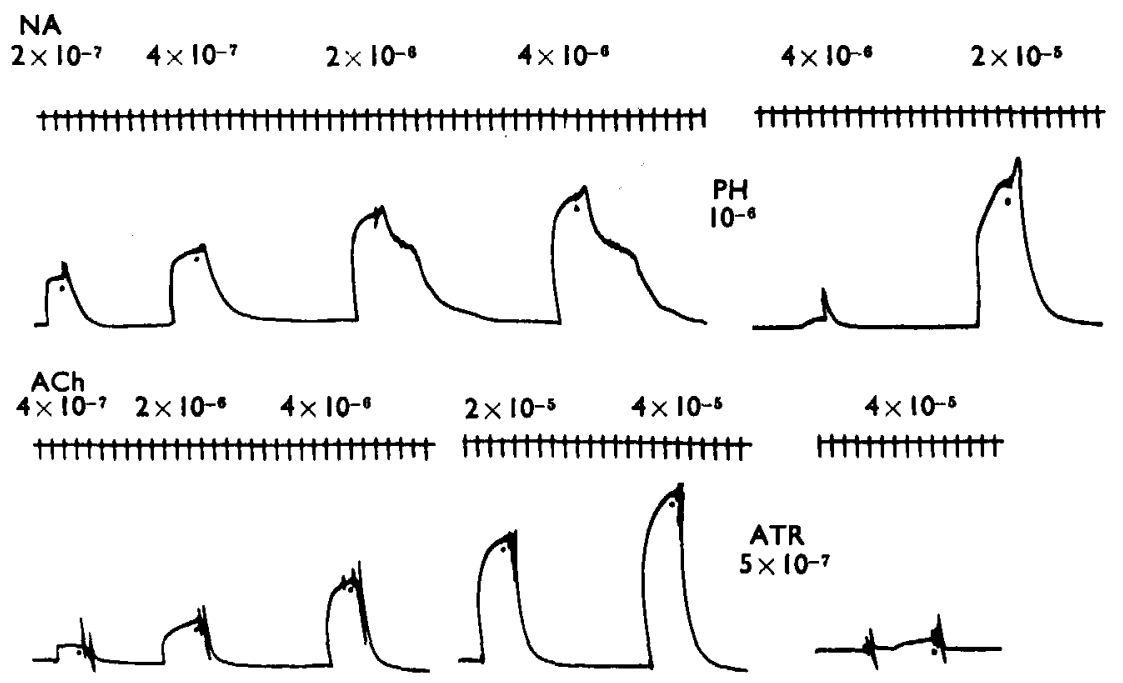

F1G. 1. The response of the rat anococcygeus to noradrenaline (NA) and acetylcholine (ACh). Upper record shows in the first panel the increasing contractions in response to increasing molar concentrations of noradrenaline. Between the first and second panel phentolamine (PH) $10^{-6} \mathrm{M}$ was added and almost completely abolished the response to a previously maximally effective dose of noradrenaline. Increasing the noradrenaline concentration restored the maximum response. Lower record shows a similar experiment in another preparation with acetylcholine and atropine. Time $30 \mathrm{~s}$. 
the absence of resting tone was investigated by examining the effect of isoprenaline on the motor response to a standard dose of noradrenaline given $20 \mathrm{~s}$ later. The result, illustrated in Fig. 2, shows that no concentration of isoprenaline exerted an inhibitory effect ; on the contrary, concentrations which were themselves ineffective potentiated the motor action of noradrenaline. The effect of propranolol on the response to noradrenaline and isoprenaline was studied. For this purpose a dose of isoprenaline sufficient to produce a motor response was used. Propranolol potentiated the response to noradrenaline and had little effect on that to isoprenaline except at high doses, where it altered the shape of the response, by inducing some low amplitude rhythmic activity at the peak of contraction.

5-Hydroxytryptamine also produced maximum contractions in this tissue, though the threshold concentration was higher at about $10^{-6} \mathrm{M}$. The muscle was almost insensitive to histamine and produced only small contractions even to doses as large as $10^{-4} \mathrm{M}$. These histamine responses showed a complete tachyphylaxis after a single dose. No other agonist drug was found to show tachyphylaxis.

\section{Effect of cholinomimetics and their antagonists}

Acetylcholine and furmethide both produced maximum contractions of the muscle with thresholds of about $2 \times 10^{-7} \mathrm{M}$. These effects were completely abolished by atropine in a concentration of $2 \times 10^{-7} \mathrm{M}$ (Fig. 1).

\section{Effect of nerve stimulation}

Field stimulation or stimulation of the extrinsic nerves produced identical motor
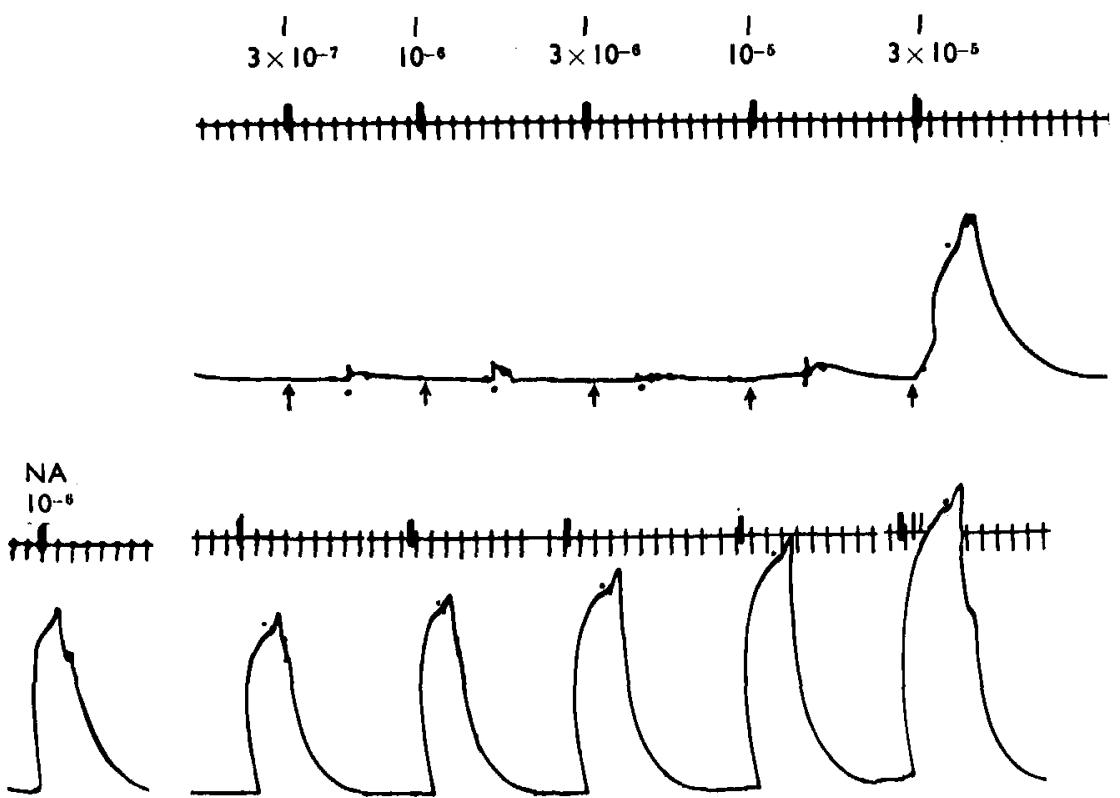

FIG. 2. The effect of isoprenaline (1) on the rat anococcygeus. In the upper panel increasing molar concentrations (shown above) of isoprenaline have no effect until a concentration of $10^{-5} \mathrm{M}$ when there is a small contraction; $3 \times 10^{-5} \mathrm{M}$ causes a larger contraction. The lower panel shows the effect of these same concentrations of isoprenaline on the response to a standard dose of noradrenaline (NA) of $10^{-6} \mathrm{M}$. There is no evidence of inhibition at any concentration; at concentrations of $3 \times 10^{-6} \mathrm{M}$ isoprenaline and greater there is potentiation of the response to noradrenaline. Time $30 \mathrm{~s}$. 
responses. Fig. 3 shows the response to field stimulation at different frequencies. A small contraction was produced at the low frequency of $1 \mathrm{~Hz}$ and this increased with increasing frequency to reach a maximum between $20 \mathrm{~Hz}$ and $40 \mathrm{~Hz}$. It was seldom possible to show a motor response to a single volley but in other experiments in vivo (Gillespie \& McGrath, unpublished) single pulses to the extrinsic nerves were effective. These effects of field stimulation were unaffected by hexamethonium even in concentrations as high as $10^{-4} \mathrm{M}$ (Fig. 3). Stimulation of the extrinsic nerve produced similar contractions of the muscle and these also were

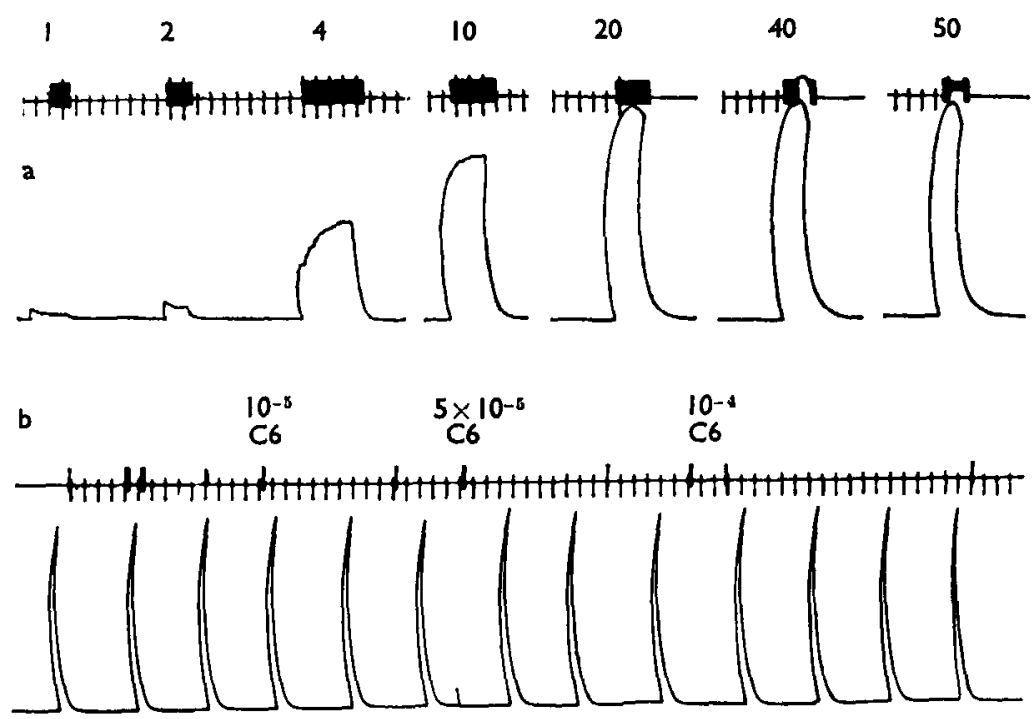

FIO. 3. The response of the rat anococcygeus to field stimulation. The upper panel shows the effect of varying the frequency which is given in $\mathrm{Hz}$ above each response. The lower panel shows the ineffectiveness of hexamethonium even in the high concentration of $10^{-4} \mathrm{M}$ in inhibiting the response. Stimulation in the lower panel at $20 \mathrm{~Hz}$. Time $30 \mathrm{~s}$.

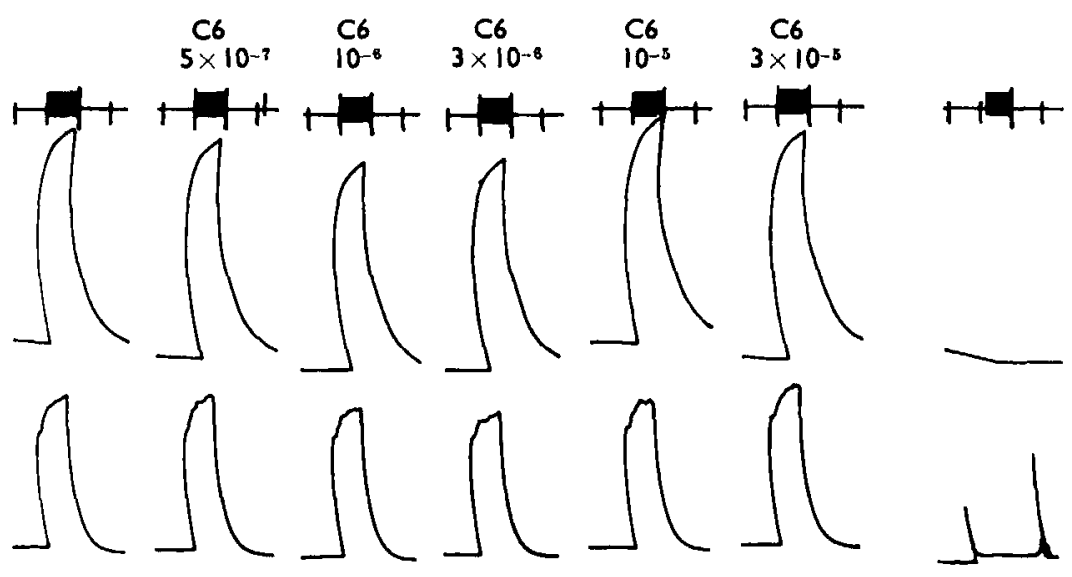

FIG. 4. The responses of each of a pair of anococcygeus muscles from the same rat to stimulation of their extrinsic nerves. Hexamethonium (C6) in the molar concentrations shown did not inhibit the response. The nerves were then cut between the stimulating electrodes and the muscle abolishing the response and demonstrating that it was due to stimulation of extrinsic nerves. 


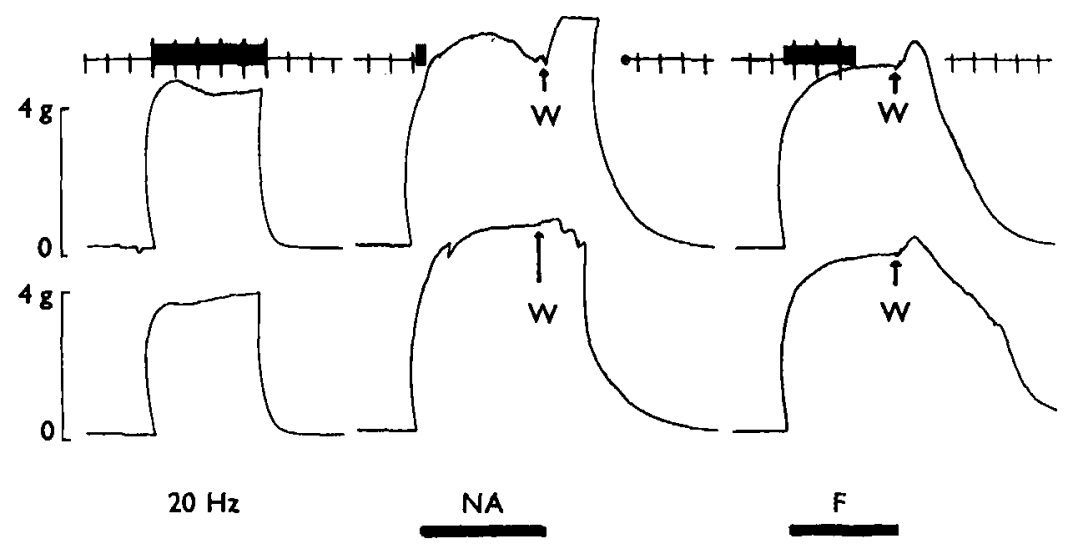

FIG. 5. The response of two anococcygeus muscles from the same rat to field stimulation at $20 \mathrm{~Hz}$ and to supramaximal concentrations of noradrenaline (NA) $10^{-5} \mathrm{M}$ and furmethide (F) $10^{-5} \mathrm{M}$. The tissues were washed at the arrows. Time $1 \mathrm{~min}$. Tension calibration for NA corresponds to $2 \mathrm{~g}$.

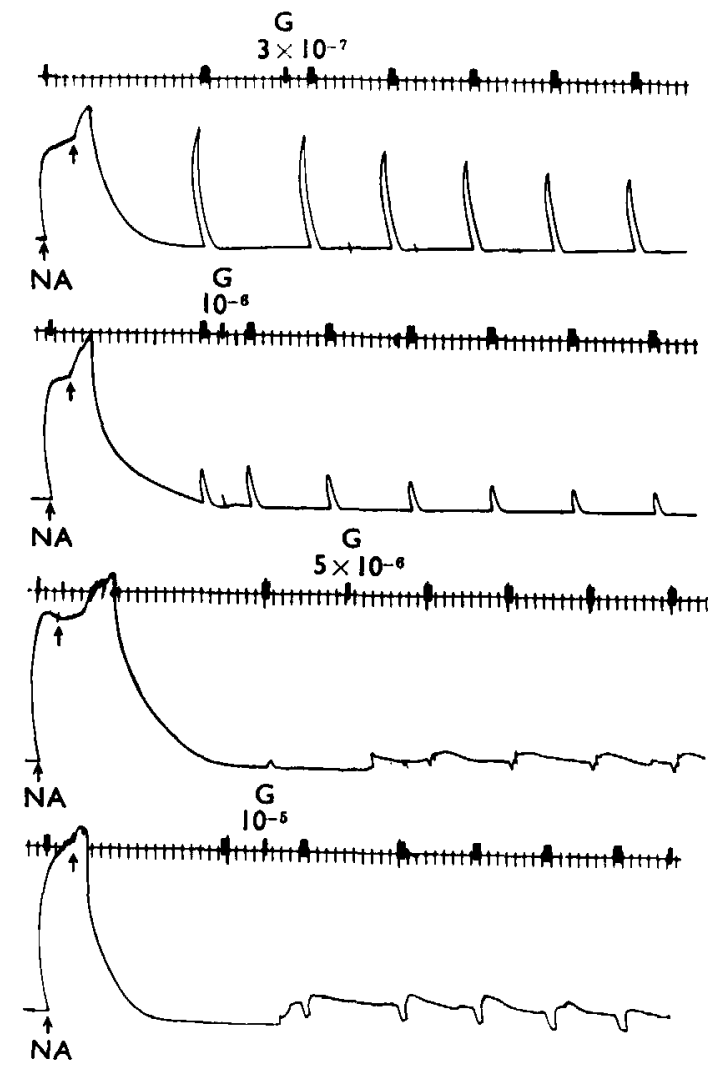

FIG. 6. The effect of increasing concentrations of guanethidine (G) on the response to field stimulation and to noradrenaline (NA). The four records are continuous. Guanethidine $3 \times 10^{-7} \mathrm{M}$ and $10^{-6} \mathrm{M}$ produces a progressive block of the motor response to field stimulation and simultaneously potentiates the response to noradrenaline $3 \times 10^{-6} \mathrm{M}$. Higher concentrations of guanethidine cause a rise in tone of the muscle and convert the response to field stimulation into first a biphasic response $\left(\mathrm{G} 5 \times 10^{-6}\right)$ and then a pure inhibitor response $\left(G^{10}\right)$. The response to noradrenaline remains motor and shows further potentiation. Time $30 \mathrm{~s}$. 
resistant to hexamethonium, though abolished by cutting the extrinsic nerves between the stimulating electrode and the preparation (Fig. 4). The motor response to field or extrinsic nerve stimulation was abolished by phentolamine but unaffected by atropine.

One of the features of the motor responses in this muscle was their maintained character ; there was little evidence of fatigue or 'fade' whether the contraction was initiated by nerve stimulation, by sympathomimetic or cholinomimetic drugs. This is illustrated in Fig. 5.

\section{Inhibitory responses}

\section{Effect of guanethidine}

The existence of an inhibitory mechanism was first revealed when the adrenergic neurone blocking agent guanethidine was investigated. The effect of this drug in increasing doses on the tone of the muscle and its response to field stimulation and noradrenaline was studied and the results are illustrated in Fig. 6. Guanethidine in low doses of about $3 \times 10^{-7} \mathrm{M}$ caused a gradually developing depression of the motor response to field stimulation and potentiated the response to noradrenaline. Higher concentrations increased the depression of the motor response to field stimulation and potentiated the response to noradrenaline. At concentrations of about $10^{-5} \mathrm{M}$ guanethidine itself caused a rise in tone and at the same time converted the response to field stimulation into a biphasic one, inhibition followed by contraction. Still further increases in the concentrations of guanethidine caused a greater rise in tone with a corresponding increase in the magnitude of the inhibition (Fig. 6). The concentration of guanethidine optimal for the demonstration of the inhibitory effect was $3 \times 10^{-5} \mathrm{M}$.

The inhibitory response uncovered by guanethidine was resistant to hexamethonium but abolished by low concentrations of tetrodotoxin, suggesting that it is due to stimulation of a nerve pathway (Fig. 7).

\section{Characteristics of the inhibitory response}

The frequency sensitivity of the inhibitory response after guanethidine was examined for comparison with the sensitivity of the motor response it replaced.

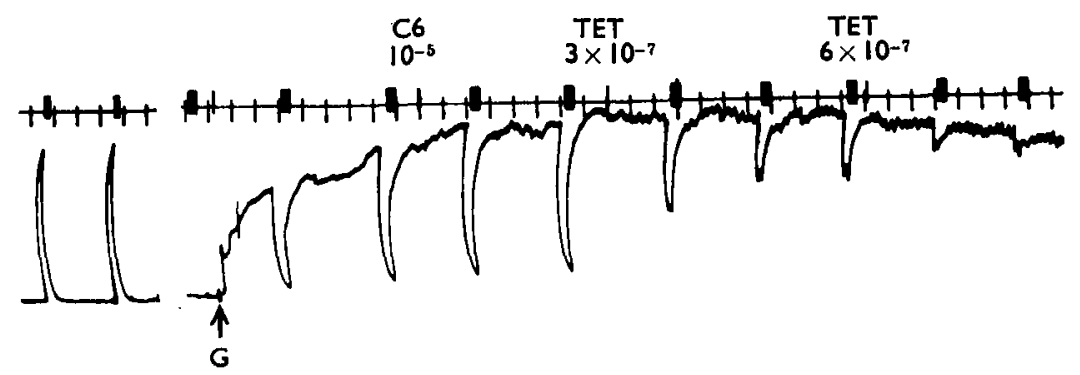

FIG. 7. The effect of hexamethonium (C6) $10^{-5} \mathrm{M}$ and tetrodotoxin (TET) $3 \times 10^{-7} \mathrm{~g} / \mathrm{ml}$ and $6 \times 10^{-7} \mathrm{~g} / \mathrm{ml}$ on the inhibitory response to field stimulation. The first panel shows the initial motor response to field stimulation. Guanethidine (G) $3 \times 10^{-5} \mathbf{M}$ was then added. This caused a rise in tone and reversal of the response to field stimulation to inhibition. Hexamethonium did not alter this inhibitory response but it was abolished by tetrodotoxin. Time $1 \mathrm{~min}$. 


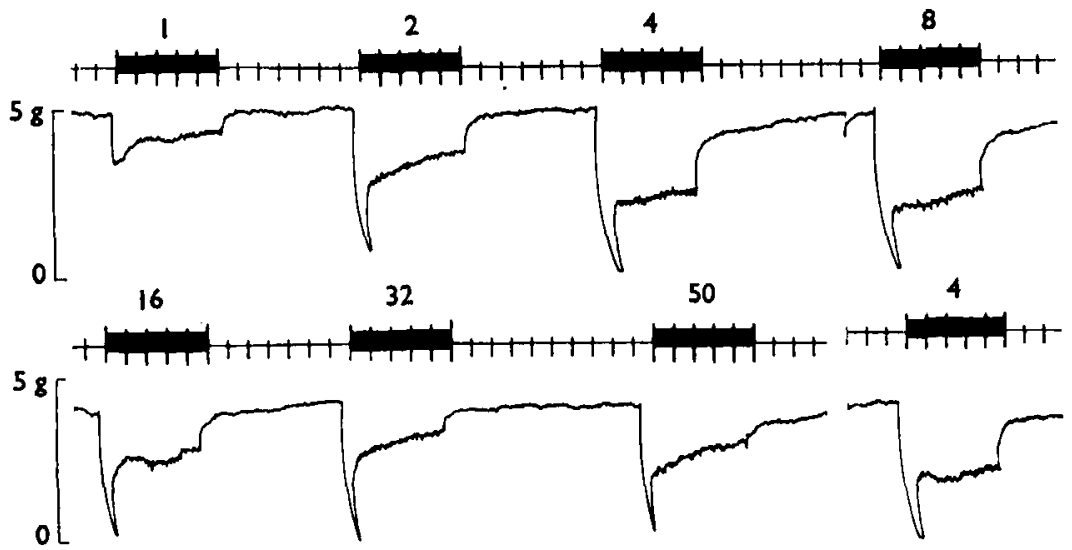

FIG. 8. Frequency-response relationship of the inhibition produced by field stimulation after guanethidine $3 \times 10^{-5} \mathrm{M}$. The tissue was stimulated for $5 \mathrm{~min}$ at the frequencies in $\mathrm{Hz}$ shown above each response. The maximum response was at $8 \mathrm{~Hz}$. Time $1 \mathrm{~min}$.

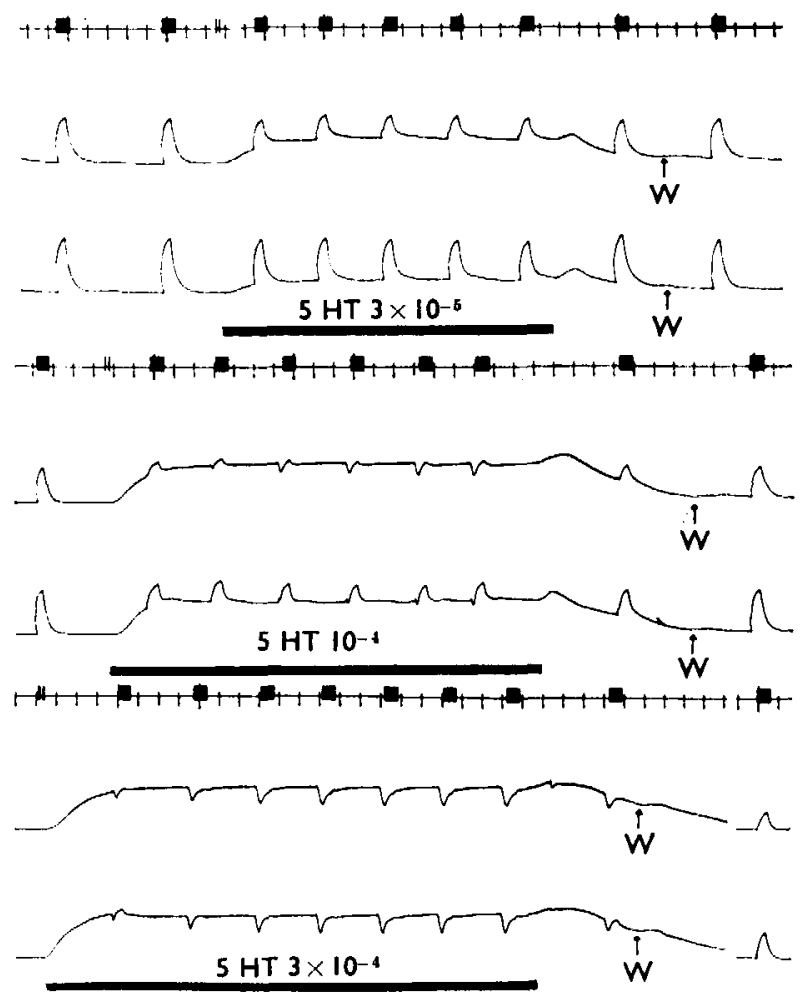

FIG. 9. The effect of 5-hydroxytryptamine (5-HT) in raising tone and reversing the motor response to inhibition. The three records are from the same pair of anococcygeus muscles exposed to progressively higher concentrations of $5-\mathrm{HT}$ for the periods shown by the black bar. In the first record $5-\mathrm{HT} 3 \times 10^{-5} \mathrm{M}$ raises tone but both muscles continue to give motor responses; in the second record $5-\mathrm{HT} 10^{-4} \mathrm{M}$ raises tone still higher and the responses in the upper muscle are reversed to inhibition but the lower remain motor. In the final record 5-HT $3 \times 10^{-4} \mathrm{M}$ causes a still greater rise in tone and now both muscles show reversal to inhibition. The motor responses are in all instances restored when the 5-HT is removed (W). Time $1 \mathrm{~min}$.

$\mathbf{R}$ 
Figure 8 illustrates one such experiment and also the fact that inhibition can be maintained for long periods. Frequencies of $1 \mathrm{~Hz}$ and less were effective in causing inhibition, the maximum response was reached at about $8 \mathrm{~Hz}$, i.e. less than the optimum for the motor response. The shape of the responses was also characteristic and not a mirror image of the motor response. There was an initial intense inhibition abolishing almost all existing tone; this was followed by a partial restoration of tone to an intermediate position which, at the optimal frequencies of stimulation, was maintained constant for the rest of the duration of stimulation.

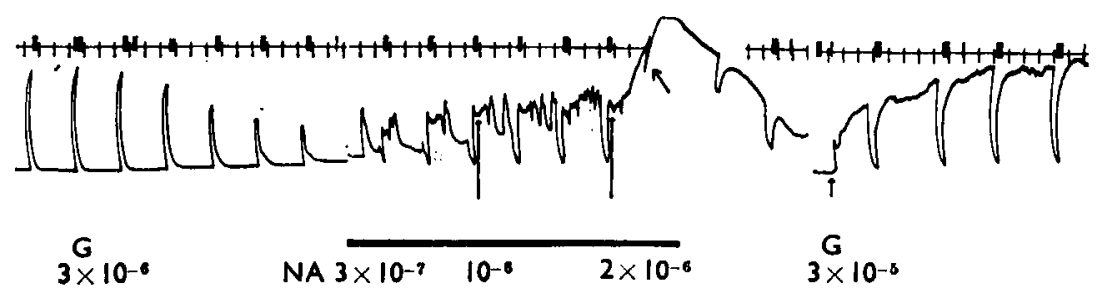

FIG. 10. The effect of raising tone by infusing various concentrations of noradrenaline (NA) during the period shown by the black bar on the response to field stimulation. The motor response to nerve stimulation had already been partially abolished by a low dose of guanethidine (G). Low doses of noradrenaline raise tone and reverse the response to inhibition but also induce rhythmic activity. Raising the concentration of noradrenaline abolishes the rhythmic activity but reduces the inhibitory response. The last panel shows the greater effectiveness of large doses of guanethidine in reversing the motor response. Time $1 \mathrm{~min}$.

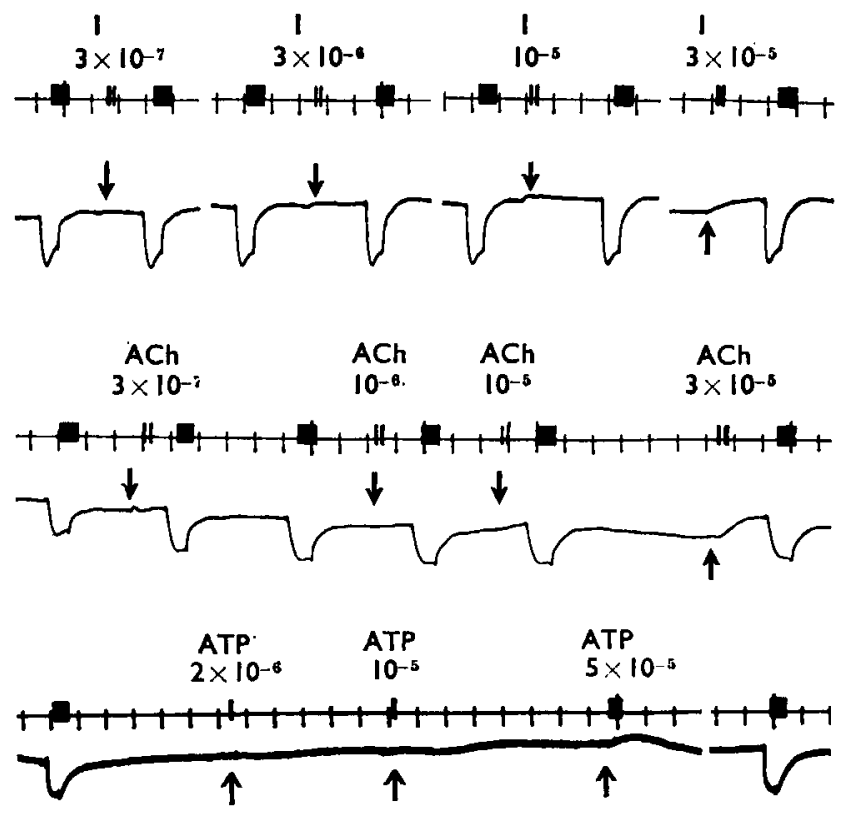

F1G. 11. The effect of increasing concentration of isoprenaline (1) (top record) acetylcholine (ACh) (middle record) and ATP (bottom record) on the rat anococcygeus at a time when field stimulation was producing inhibition. The records are from three different experiments and in each guanethidine was used to reverse the response. Neither acetylcholine, isoprenaline nor ATP produced inhibition at any concentration. All produced small motor responses at high concentrations without altering the inhibitory response to field stimulation. 


\section{Inhibition after other drugs which raise tone}

The purpose of these experiments was to see whether the ability of guanethidine to reverse the motor response to inhibition was a unique property of the drug or the result of its ability to block the motor adrenergic nerves at the same time as it caused a rise in tone on which inhibition could be demonstrated. Experiments were therefore carried out to see whether simply raising tone by means of other agonist drugs would reverse the response to field stimulation from motor to inhibitory. Three drugs were examined, 5-hydroxytryptamine, acetylcholine and noradrenaline itself. 5-Hydroxytryptamine flushed slowly through the bath produced a rise in tone graded with the drug concentration. As Fig. 9 shows, when the tone was raised higher than the maximum of the motor response in the absence of 5-hydroxytryptamine, the response to stimulation was reversed to inhibition. It was more difficult to reverse the response when tone was raised by noradrenaline itself, but Fig. 10 shows that if guanethidine was used in a concentration which reduced but did not abolish the motor response and then the tone raised by slow flushing of the bath with noradrenaline solution, the residual motor response to field stimulation was reversed to inhibitory. If sufficient guanethidine was used to raise tone and so itself reverse the response to inhibition then further increases in tone by increasing the concentration of noradrenaline did not increase but rather reduced the amplitude of the inhibitory response, presumably by physiological antagonism (Fig. 10).

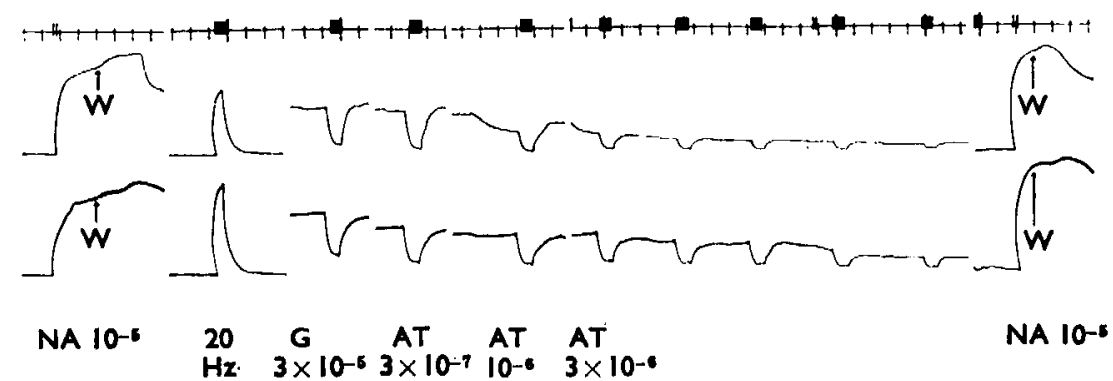

PIG. 12. The effect on the inhibitory response of the anococcygeal muscle to field stimulation of increasing molar concentrations of atropine (AT). The first panel shows the maximum response to noradrenaline (NA) $10^{-5} \mathrm{M}$, the second the motor response to field stimulation before guanethidine. Guanethidine (G) $3 \times 10^{-5} \mathrm{M}$ raises tone and cosverts the motor response to inhibition. Atrepine in increasing concentrations lowers tone and thereby diminishes the magnitude of the imhibitory response but never abolishes it. The last record shows that atropine does not diminish the response to noradrenaline. Time $1 \mathrm{~min}$.

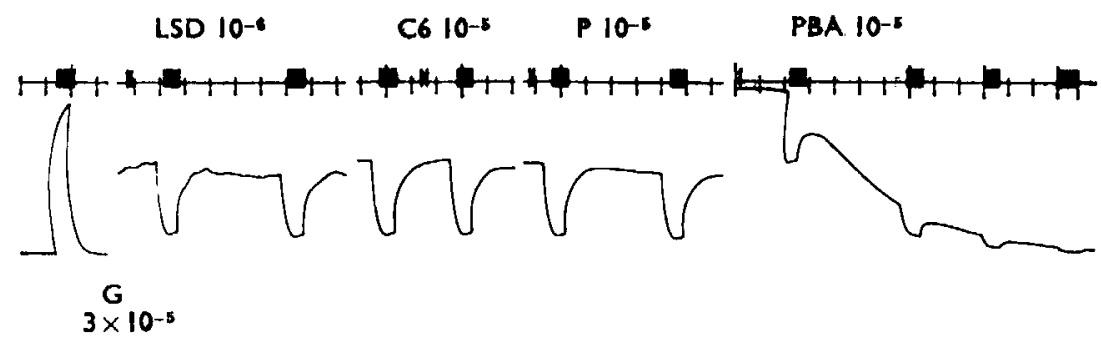

FIG. 13. The inhibitory response to field stimulation after guanethidine (G) is unaffected by LSD $10^{-6} \mathrm{M}$, hexamethonium (C6) $10^{-5} \mathrm{M}$ or propranolol $(\mathrm{P}) 10^{-} \mathrm{M}$. Phenoxybenzamine (PBA) abolishes the muscle tone and so diminishes the magnitude of the inhibitory response but otherwise does not influence it. Time $1 \mathrm{~min}$. 
These experiments showed that the reversal of the response by guanethidine was not a unique property of this drug, nor indeed confined to adrenergic neurone blocking agents. Nonetheless, it was found that the amplitude of the inhibitory responses after large doses of guanethidine were consistently greater than those produced by any other method, possibly because of the combination of simultaneous block of the motor adrenergic responses and an indirect sympathomimetic rise in tone.

\section{The effect of potential inhibitory transmitters}

The action of three potential inhibitory transmitters, acetylcholine, isoprenaline and ATP in a range of concentrations was examined at a time when field stimulation was causing inhibition. None caused inhibition; all at high concentrations caused contraction. Figure 11 shows these effects. Acetylcholine in concentrations below $10^{-5} \mathrm{M}$ had no effect by itself, nor did it influence the inhibitory response to field stimulation. A concentration of $10^{-5} \mathrm{M}$ and even more $3 \times 10^{-5} \mathrm{M}$ acetylcholine caused a further rise in tone with little change in the inhibitory response. Similarly low concentrations of isoprenaline or ATP had no effect, higher concentrations caused contraction, no concentration had any effect on the inhibition resulting from field stimulation.

\section{The effects of potential inhibitors of the inhibitor response}

Six drugs were studied, atropine, phentolamine, phenoxybenzamine, propranolol, lysergic acid diethylamide and hexamethonium. None abolished the inhibitory response, although phentolamine, phenoxybenzamine and, rather surprisingly, atropine abolished the tone produced by guanethidine and to the extent they did this so they reduced the ability to demonstrate inhibition. Figure 12 shows the effect of atropine. In low concentrations this had little or no effect, at $10^{-6} \mathrm{M}$ or higher there was a gradual decline in tone with a corresponding diminution of the inhibitory response but this was not abolished. In spite of the reduction in tone produced by guanethidine the response to noradrenaline was unimpaired. Figure 13 shows the inability of LSD, hexamethonium or propranolol to alter the inhibitory response. Phenoxybenzamine $10^{-5} \mathrm{M}$ produced an almost complete loss of tone and correspondingly almost completely prevented the demonstration of the inhibitory response, but there was no evidence of its abolition.

\section{Discussion}

The in vitro rat anococcygeus is a convenient smooth muscle preparation which should be useful both for teaching and research. It is easily isolated and has the advantages claimed in the opening paragraph of this paper.

Its response to the chemical transmitter substances suggests that it is well endowed with conventional muscarinic and $\alpha$-adrenoceptors, but that $\beta$-receptors are few or non-existent. Any which are present appear to mediate motor responses. 5-Hydroxytryptamine is also an effective agonist, though no analysis of the type of receptor involved was carried out. Histamine, on the other hand, is almost ineffective.

Histologically, the adrenergic motor innervation most nearly resembles that of 
the nictitating membrane, which the muscle also resembles in its lack of spontaneous activity and tone. Like the nictitating membrane, the anococcygeus is probably a multi-unit type of muscle and it will be interesting to see if there is a corresponding lack of tight junctions and poor electrical conductivity between cells. The inability of hexamethonium in high doses to alter in any way the response to field stimulation, or to stimulation of the extrinsic nerves some 1 to $2 \mathrm{~cm}$ from the muscle, suggests that the innervation, unlike that of the vas deferens, is by the more conventional long adrenergic neurones. Experiments in vivo (Gillespie \& McGrath, unpublished) have confirmed this.

The most interesting observation is certainly the inhibitory response to field stimulation after the administration of guanethidine. This appears to be due to nerve stimulation, since it is abolished by tetrodotoxin in doses which do not abolish muscle tone or the agonist action of noradrenaline. The nature of this inhibition is obscure. It could either be the release of an inhibitory substance or a temporary abolition of the action of guanethidine in raising tone. Guanethidine raises tone by releasing noradrenaline from the stores in the terminal adrenergic nerve fibres. If action potentials in these adrenergic nerves were somehow to abolish this action of guanethidine, then inhibition would result. This, however, is not the explanation, since substances such as 5-HT or furmethide, which raise tone by acting on muscle receptors, can also uncover an inhibitory effect. It seems that stimulation releases some as yet unknown inhibitory transmitter. Whether this substance is released from adrenergic nerves at a time when noradrenaline release is blocked, or whether there is a parallel innervation by another set of nerves has still to be determined. The nature of the inhibitory transmitter is also unknown. It is not acetylcholine, isoprenaline or ATP. Burnstock, Campbell, Satchell \& Smythe (1970) have produced evidence for ATP or ADP as the likely transmitter in non-adrenergic inhibitory nerve fibres in the alimentary canal. ATP is not the inhibitory transmitter in the anococcygeus, since at low doses it is without effect and at high doses produces a motor response. ADP was not tested but it is unlikely to fit the role, since almost certainly some would be produced in the bath when the very high concentrations of ATP were added. Nor is it likely that the inhibitory transmitter is identical with the unknown motor transmitter postulated by Ambache, Dunk, Miall \& Zar (1971) in the vas deferens, since the effects of that nervous pathway are abolished by LSD, which has no effect on inhibition in the anococcygeus, though admittedly longer trains of stimuli were used. Other possible transmitters still to be investigated are the fatty acid derivatives, particularly the prostaglandins, and amino-acids such as glycine.

Guanethidine is the most effective drug in uncovering inhibition. Apparently there are two requirements for optimum inhibitory responses and both are met by guanethidine. First, the tone of the preparation must be raised, and secondly, the motor adrenergic response blocked. Presumably noradrenaline liberated by the adrenergic nerves at the same time as the inhibitory transmitter acts as a physiological antagonist-certainly noradrenaline added to the bath when the tone is already raised reduced the inhibitory response to field stimulation.

I am most grateful to the M.R.C. and to the Rankin Medical Research Fund for apparatus, and to Miss H. McCaffrey for her patient and skilful technical assistance.

REFERENCES

Ambachf, N., Dunk, Linda P., Miall, P. \& Zar, A. M. (1971). Unexplained inhibitory action of D-Lysergic acid diethylamine (LSD) on post-ganglionic motor transmission in the guinea-pig vas deferens, Br. J. Pharmac., 42, 659P. 
BURN, J. H. \& RAND, M. J. (1960). The relation of circulating noradrenaline to the effect of sympathetic stimulation. J. Physiol., 150, 295-305.

Burnstock, G., Campbell, G., Satchell, D. \& Smythe, Anne (1970). Evidence that adenosine triphosphate or a related nucleotide is the transmitter substance released by non-adrenergic inhibitory nerves in the gut. Br.J. Pharmac., 40, 668-688.

GILLESPIE, J. S. (1971). The rat anococcygeus; a new, densely innervated smooth muscle preparation. Br.J. Pharmac., 43, 430.

Gillespie, J. S. \& KIRPEKAR, S. M. (1966). The histological localisation of noradrenaline in the cat spleen. J. Physiol., 187, 69-79.

Gillespie, J. S. \& MaXwel, J. D. (1971). Adrenergic innervation of sphincteric and nonsphincteric smooth muscle in the rat intestine. J. Histochem. Cytochem., 19, 676-681.

Koelle, C. B. (1955). The histochemical identification of acetylcholinesterase in cholinergic, adrenergic and sensory neurones. $J$. Pharmac., 114, 167-184.

(Received February 28, 1972) 